\title{
PLANO DE GERENCIAMENTO DE RESÍDUOS EM INSITUIÇÕES DE LONGA PERMANÊNCIA PARA IDOSOS (ILPI) DURANTE A PANDEMIA DA COVID-19
}

Cristiane dos Santos Rosa'

ORCID: 0000-0002-6001-7053

Lucimar de Souza Campos"

ORCID: 0000-0002-2863-5337

Rosimere Ferreira Santana"II

ORCID: 0000-0002-4593-3715

"ILPI- Espaço Vianney. Rio de Janeiro, Rio de Janeiro, Brasil.

"' Lar de Convivência Iclea de Sá - Lar Jolie. Rio de Janeiro, Rio de Janeiro, Brasil.

I"' Universidade Federal Fluminense. Rio de Janeiro, Rio de Janeiro, Brasil.

Autor Correspondente:

Cristiane dos Santos Rosa

E-mail: contatocristianerosa@gmail.com

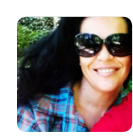

Como citar:

Rosa CS, Campos LS, Santana RF. Gerenciamento de resíduos em instituições de longa permanência para idosos durante a pandemia da covid- 19 . In: Santana RF. Enfermagem gerontologica no cuidado do idoso em tempos da COVID 19.

2.ed.rev. Brasilia, DF: Editora ABEn; 2020. p.35-43.

(Serie Enfermagem e Pandemias, 1). https://doi.org/10.51234/aben.20.e01.c06

\section{INTRODUÇÃO}

A pandemia causada pelo coronavírus, que tem como grupo vulnerável idosos e portadores de doenças crônicas, atrai a atenção da sociedade para um cenário carregado de estigmas, preconceitos e heterogeneidade que são as Instituições de Longa Permanência para Idosos. Legalmente são espaços de caráter residencial, destinadas a domicílio coletivo de pessoas com idade igual ou superior a 60 (sessenta) anos, com ou sem suporte familiar, em condições de liberdade, dignidade e cidadania (SOUZA; E-GOVERNADOR; DORNELLES, 2018).

Coronavírus, representa uma grande família de vírus responsável por outras epidemias no passado, e que se apresenta agora como a SARS-CoV-2, agente etiológico causador a doença pelo coronavírus 2019 (COVID-19) que começou em Wuhan, na China, no final de 2019 e se espalhou por todo o mundo (FOR; COVID-, 2020).

No Brasil, começam a ser noticiados os primeiros casos de COVID 19 em ILPIs e rígidas medidas de controle passam a ser tomadas dentro destas estruturas que até então não eram consideradas partes da assistência á saúde e, sim da assistência social. Em poucos dias, pessoas e estruturas tiveram que se adaptar a uma forma de cuidado com distanciamento, ao isolamento, aos Equipamentos de Proteção Individual (EPIs), ao risco eminente de uma tragédia com a ocorrência de mortes sequenciais e, corresponsabilidade pela proteção uns dos outros.

Ao considerar que um idoso residente em uma ILPI, infectado pelo coronavirus, com apresentação de quadro leve da COVID 19, vai permanecer em isolamento dentro da instituição, o profissional enfermeiro responsável pelo gerenciamento dessa assistência e, obrigatoriamente, construir um plano de ação que contemple a coletividade visto o potencial de contágio da doença que chega a ser de 1 para 2.38 . 
Nesse contexto dicotômico, onde a ILPI, não é um serviço da saúde, porém, por lei tem que oferecer assistência em saúde no enfrentamento de uma pandemia marcada por deixar a mostra a fragilidade do mundo, com relação a oferta de EPIs e medidas protetivas, para a população vulnerável ainda deve-se focar em mitigação de danos ao indivíduo, á coletividade e ao meio ambiente.

Essas reflexões trazem a tona um problema real e que pode vir a contribuir ainda mais com a proliferação da doença caso não lhe seja dado a devida atenção: o gerenciamento de Resíduos de Serviços em Saúde. Que são definidos pela RDC 222/2018 como compostos por diferentes frações geradas nos estabelecimentos de saúde, compreendendo desde os materiais perfuro-cortantes contaminados com agentes biológicos, peças anatômicas, produtos químicos tóxicos e materiais perigosos como solventes, quimioterápicos, vidros vazios, papelão, papel de escritório, plásticos e restos de alimentos.

Os resíduos supracitados gerados e manipulados de forma inadequada no ambiente podem contribuir para as poluições biológicas, físicas e químicas do solo, da água e do ar, submetendo as pessoas às variadas formas de exposição ambiental. O gerenciamento inadequado dos Resíduos de Serviços de Saúde na assistência tem gerado um aumento do número de colaboradores acometidos por acidentes de trabalho, além de contribuir para o aumento da incidência de infecção.

Segundo as normativas legais, toda ILPI tem que apresentar um programa de gerenciamento de resíduo, contudo ao buscar-se subsídios para esse trabalho na RDC 222/2018 não se encontra uma única citação sobre esse estabelecimento para residências coletivas.

Os serviços citados como geradores de Resíduos de Serviços de Saúde são: todos os serviços cujas atividades estejam relacionadas com a atenção à saúde humana ou animal, inclusive os serviços de assistência domiciliar; laboratórios analíticos de produtos para saúde; necrotérios, funerárias e serviços onde se realizem atividades de embalsamamento (tanatopraxia e somatoconservação); serviços de medicina legal; drogarias e farmácias, inclusive as de manipulação; estabelecimentos de ensino e pesquisa na área de saúde; centros de controle de zoonoses; distribuidores de produtos farmacêuticos, importadores, distribuidores de materiais e controles para diagnóstico in vitro; unidades móveis de atendimento à saúde; serviços de acupuntura; serviços de piercing e tatuagem, salões de beleza e estética, dentre outros afins. (RDC 222/2018).

Portanto, considerando que a produção do lixo infectante desses serviços terá um aumento substancial e, que esse pode contribuir negativamente com a propagação do vírus além dos muros da instituição. Já que estudos mostram que o a transmissão pode se dar também pelas fezes, e que um dos sinais da COVID-19 é a diarreia, contribuindo para o aumento de uso de fraldas e seu descarte. Considerando o uso de EPIs descartados após o uso e tudo mais que compõe os insumos utilizados no isolamento se faz necessário que as instituições tenham maior subsidio teórico para o acondicionamento, transporte e descarte desses rejeitos. Dessa maneira busca-se manter os princípios de biossegurança e o correto gerenciamento de todos os RSS por elas geradas, atendendo às normas e exigências legais, desde o momento de sua geração até a sua destinação final.

\section{OBJETIVO}

Oferecer subsídios para a construção e/ou aprimoramento de um plano de gerenciamento de resíduos em Instituição de Longa Permanência para Idosos no contexto da pandemia por coronavírus

\section{MÉTODO}

Reflexão teoria tendo como eixo norteador a RDC №222/2018 e as portarias publicadas pela Anvisa de janeiro de 2020 até o presente momento. 


\section{RESULTADOS}

\section{ELEMENTOS PARA ELABORAÇÃO DE UM PROGRAMA DE GERENCIAMENTO DE RESIDUOS EM TEM- POS DA COVID-19}

A elaboração e implantação do Programa de Gerenciamento de Resíduo em Serviços de Saúde (PGRSS) em ILPIs é uma exigência legal para o funcionamento dessas instituições perante os órgãos sanitários municipais. Em sites especializados e na própria RDC №222/2018 encontram-se modelos de roteiros para montagem deste instrumento.

Todavia, a situação imposta pela pandemia, exige ações mediadas por evidências cientificas e que sejam realmente resolutivas e aplicáveis a realidade de cada instituição. Não cabe, na atual conjuntura, a confecção de instrumentos somente para cumprir exigências legais.

Por isso, vale elencar os elementos básicos para a elaboração ou implementação de um PGRSS em tempos de COVID 19.

A) Diagnóstico da situação: a instituição ter um PGRSS implantado e funcional é condição para que se parta para as adaptações frente a nova realidade. Caso não tenha o Plano de Gerenciamento de Resíduos, o fluxograma 1 poderá elencar os principais pontos para sua elaboração, que deve ser construído a partir do arcabouço legal e da realidade vivida em cada instituição.

B) Educação permanente: investir no fator humano é fundamental para mitigar riscos de acidentes e contaminação do ambiente. Todavia, a avaliação sistemática dos processos deve fazer parte do dia a dia do PGRSS. Para a prevenção de acidentes e exposição do trabalhador e agentes biológicos devem ser adotadas as seguintes medidas:

- Durante o manuseio dos resíduos o funcionário deverá utilizar os seguintes equipamentos de proteção individual, luvas: de PVC ou borracha, impermeáveis, resistentes, de cor clara, antiderrapantes e de cano longo; e avental: de PVC, impermeável e de médio comprimento.

- Após a coleta interna, o funcionário deve lavar as mãos ainda enluvadas, retirando as luvas e colocando-as em local apropriado. O funcionário deve lavar as mãos antes de calçar as luvas e depois de retirá-las.

- Em caso de ruptura das luvas, o funcionário deve descartá-las imediatamente, não as reutilizando.

- Esses equipamentos de proteção individual devem ser lavados e desinfetados diariamente. Sempre que houver contaminação com material infectante, devem ser substituídos imediatamente, lavados e esterilizados.

- Não fumar e não alimentar-se durante o manuseio com resíduos.;

- Retirar as luvas e lavar as mãos sempre que exercer outra atividade não relacionada aos resíduos (ir ao sanitário, atender o telefone, beber água, etc.);

- Manter o ambiente sempre limpo e organizado;

- O uniforme deve, preferencialmente, ser lavado pela instituição;

- O profissional deve ser orientado a tomar banho ao final do turno de trabalho.

As pessoas envolvidas com o manuseio de resíduos devem ser submetidas a exame admissional, periódico, de retorno ao trabalho, mudança de função e demissional. Os exames e avaliações que devem ser submetidas são: Anamnese ocupacional, Exame físico, Exame mental. Os funcionários também devem ser vacinados contra tétano, hepatite e outras considerações importantes pela Vigilância Sanitária. 


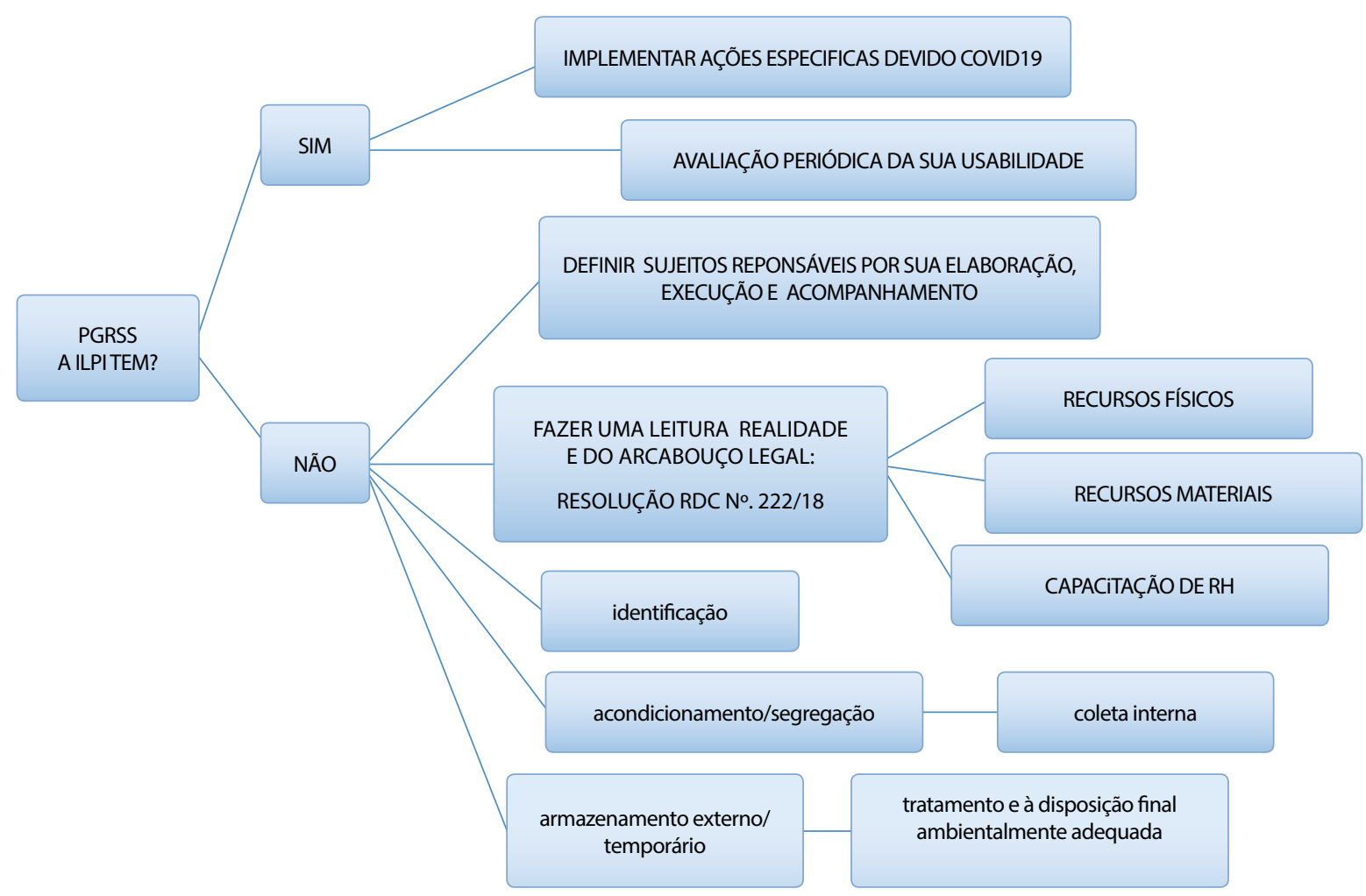

Figura1: Fluxograma exemplificando os itens para construção do Plano de Gerenciamento de Resíduos em ILPI. Brasil, 2020

C) A ILPI DEVE CLASSIFICAR E ACONDICIONAR OS RESÍDUOS DOS SERVIÇOS DE SAÚDE: A classificação dos Resíduos de Serviços de Saúde objetiva destacar a composição desses resíduos segundo as suas características biológicas, físicas, químicas, estado da matéria e origem, para o seu manejo seguro. A classificação dos resíduos, produzidos pelos serviços de saúde, em A,B, C, D e E vai determinar todos os passos para cada tipo de resíduo como tipo de acondicionamento, cuidados no transporte e destinação final. Basicamente, a ILPI irá produzir resíduos do tipo A (Curativo, EPIs descartáeis, fralda e lenços no caso da COVID19), tipo B (frascos de medicamentos), tipo D (resíduos comuns eu podem ser acondicionados em saco preto) e tipo $\mathrm{E}$ (lancetas, agulhas, lâminas). Vale ressaltar que legalmente a instituição deve estabelecer um contrato com uma empresa especializada para o recolhimento destes resíduos e sua correta destinação. Como o pagamento por este serviço será feito com base no peso deste, uma segregação errada onde se mistura resíduos comuns com infectantes, vai impactar economicamente a gestão de recursos financeiros.

D) No que se refere ao resíduo produzido durante a assistência ao idoso em isolamento de vido COVID 19 é a figura 3 ilustra como exemplos EPIs utilizados durante a assistência, fralda, material de curativo, etc. Salienta-se a importância do descarte desses materiais ocorrer dentro do ambiente de isolamento em lixeira acionada por pedal em saco vermelho. Ter um ou mais idosos nesta condição dentro da ILPI vai impactar a produção de resíduo infectante dentro do serviço. Sabe-se que parte das instituições privadas necessitam legalmente de estabelecer contratos com empresas prestadoras de serviço, e que cobram por peso pelo recolhimento e tratamento do lixo infectante, nota-se aí a importância econômica de se estabelecer processos que otimizem sua segregação e acondicionamento adequado. 

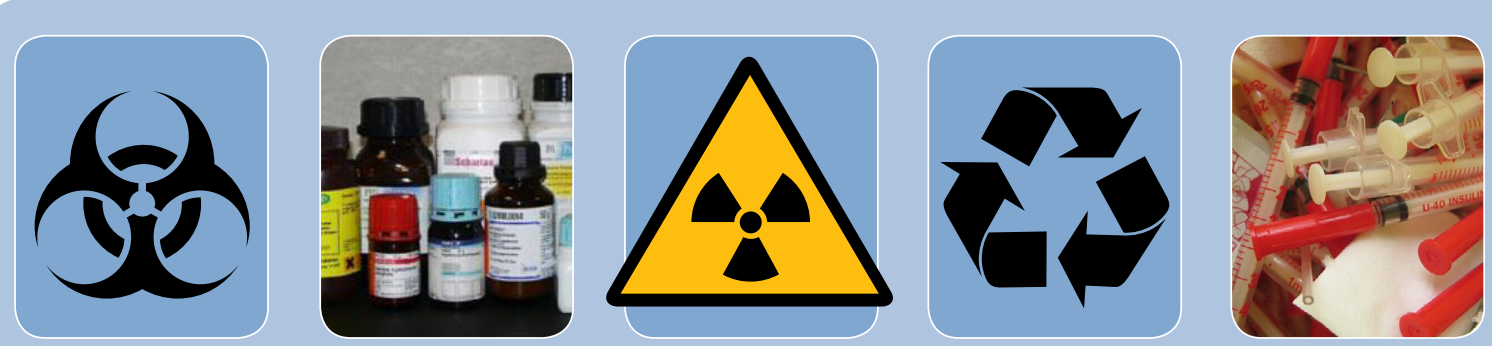

RESIDUO INECTANTE.

PRESENÇA DE

SECREÇÃOE

FLUÍDOS COM

POTENCIAL DE

CONTAMINAÇÃO.

USAR SACO BRANCO OU VERMELHO
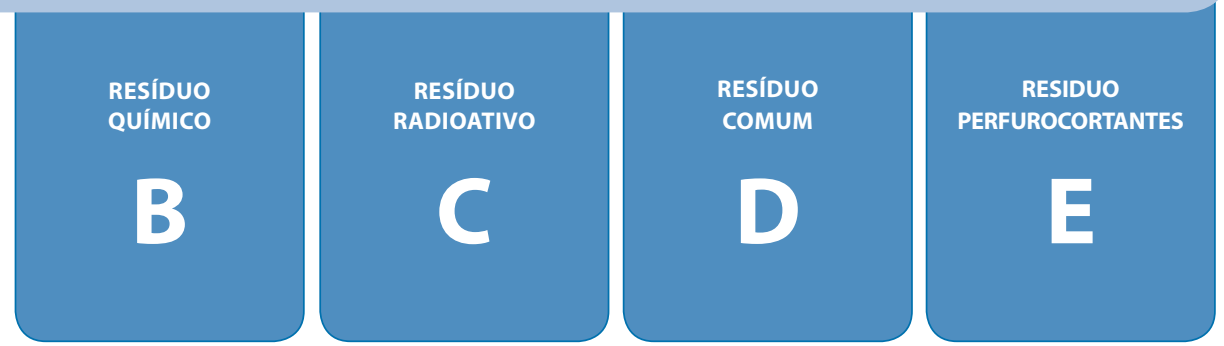

Figura 2: Classificação dos resíduos produzidos em ILPI. Brasil, 2020.

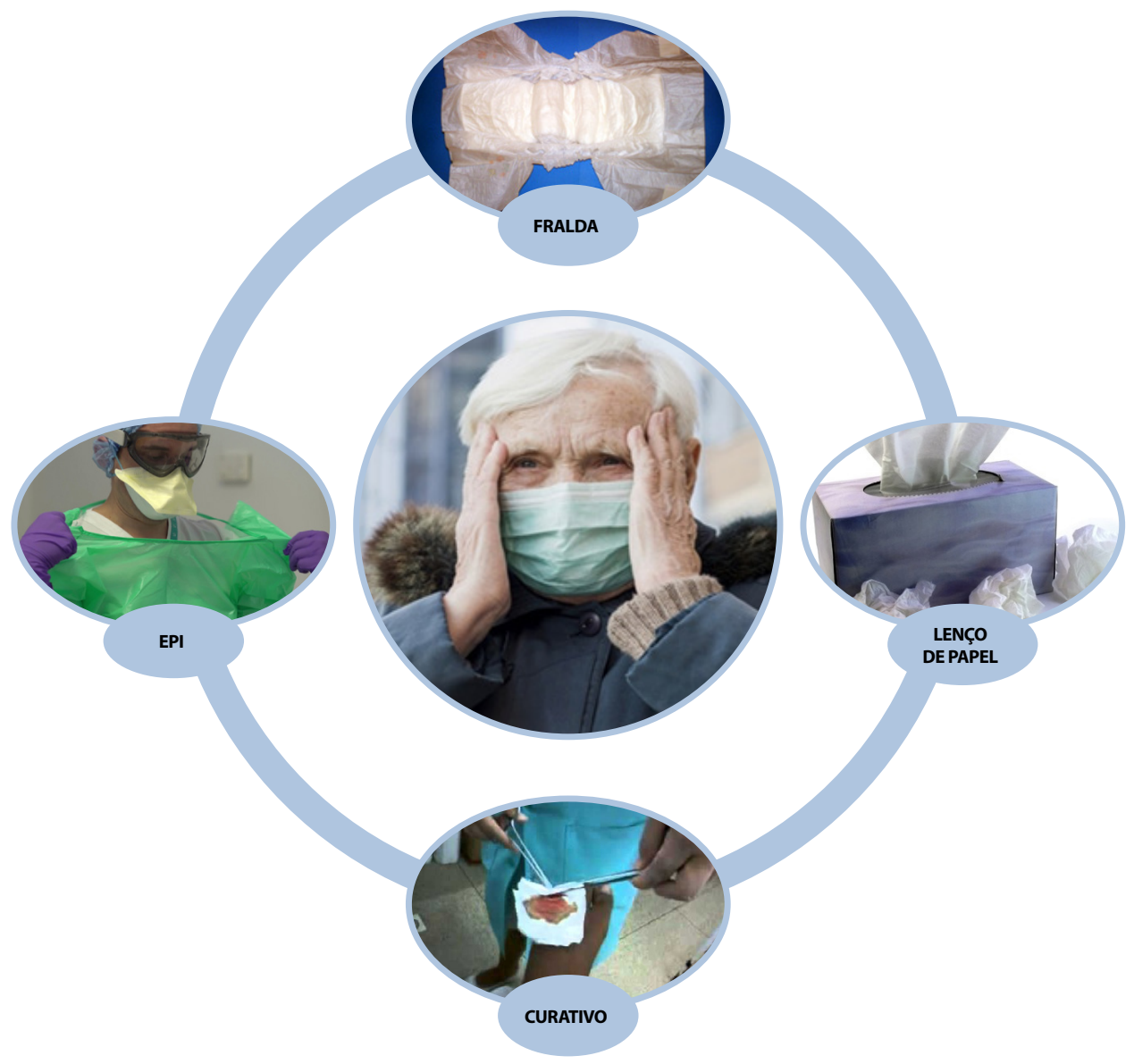

Figura 3: Principais tipos de resíduos produzidos em ILPI. Brasil, 2020. 
E) COLETA INTERNA DOS RESÍDUOS: Os resíduos deverão seguir os seguintes procedimentos ao serem transportados dentro do estabelecimento, de acordo com as Resoluções RDC - ANVISA n 222/2018 e do município sede do estabelecimento.

- O transporte dos recipientes deve se realizado sem esforço excessivo ou risco de acidente para o funcionário.

- Os procedimentos devem ser realizados de forma a não permitir o rompimento dos recipientes. No caso de acidente ou derramamento, deve-se imediatamente realizar a limpeza e desinfecção simultânea do local e notificar.

F) ABRIGO DOS RESÍDUOS: Os resíduos deverão seguir os seguintes procedimentos ao serem transportados dentro do estabelecimento, de acordo com as Resoluções RDC - ANVISA n² 288/2018, do município sede do estabelecimento.

- Os resíduos provenientes dos cuidados com residentes suspeitos ou confirmados da COVID-19 na ILPI devem ser enquadrados na categoria A1 - Resíduos com risco biológicos, altamente infectantes, incluindo: recipientes e materiais resultantes do processo de assistência à saúde, contendo sangue ou líquidos corpóreos na forma livre (algodão, gaze, compressas com matéria orgânica, fraldas, sondas entre outros). As agulhas e o conjunto seringa-agulha utilizadas na aplicação de vacinas, quando não desconectadas, devem atender às regras de manejo dos resíduos perfuro cortantes.

- No caso das ILPI com tratamento realizado fora da unidade, estes resíduos devem será condicionados em sacos vermelhos, permanecer armazenados em abrigo para resíduos;

- O abrigo de resíduos deve ser constituído de um local fechado, ser exclusivo para guarda temporária de resíduos de serviços de saúde, devidamente acondicionados em recipientes.

- Os recipientes de lixo devem ser colocados local fechado, exclusivo para guarda temporária, rígidos, resistentes a ruptura e vazamentos, com tampa provida de controle de fechamento e identificados.

- As dimensões do abrigo devem ser suficientes para armazenar a produção de resíduos de até três dias, sem empilhamento dos recipientes acima de 1,20 m.

- O piso, paredes, porta e teto devem ser de material liso, impermeável, lavável e de cor branca.

- A porta deve adotar o símbolo de substância infectante.

- O abrigo de resíduo deve ser higienizado após a coleta externa ou sempre que ocorrer derramamento.

G) A higienização dos contêineres deve ser realizada sempre após a coleta externa, seguindo os seguintes passos:

- lavar com água e sabão;

- enxaguar com água limpa;

- deixar escorrer;

- realizar a desinfecção com hipoclorito de sódio a 1\% aplicar com pano limpo, deixar agir por 10 minutos;

- enxaguar com água limpa em abundância;

- secar antes de colocar os sacos de lixo.

H) Cuidados com utensílios de limpeza

- Escovas - Devem ser lavadas com água e sabão diariamente após o uso e postas para secar;

- Baldes - Devem ser lavados diariamente ou desinfetados. Guarda-los limpos, secos e embocados; 
- Panos - Após o uso, devem ser lavados com água e sabão e após limpeza devem ser desinfetados com hipoclorito a $1 \%$.

\section{GERENCIAMENTO DE RESÍDUOS EM ILPI EM TEMPOS DE COVID}

O entendimento e fortalecimento dos elos do gerenciamento de resíduo em serviços que oferecem cuidados em saúde, no estudo em questão, a ILPI em tempos de COVID19 são essenciais para que não se perpetue a cadeia de transmissão.

Segundo os principais órgãos regulatórios sobre gerencialmente de resíduos provenientes das atividades assistenciais de pacientes suspeitos ou confirmados de infecção pelo novo Coronavírus (COVID-19) devem ser classificados como resíduos de serviços de saúde do Grupo A (sub grupo A1), risco biológico, resíduos com presença de agentes biológicos classe de risco 3 que, por suas características, podem apresentar sendo sua transmissão de alto risco individual e moderado risco para a comunidade (ANVISA, 2020).

De modo a simplificar os conceitos e as etapas para o melhor gerenciamento destes resíduos, segue abaixo um quadro com uma breve explicação de cada um. Para o enfermeiro responsável pela equipe e pelo meio que o cerca é essencial que se apodere deste conhecimento para construção de uma prática de cuidado segura par todos.

Quadro 1: Simplificação do conceitos fundamentais para a formulação de uma PGRSS.

\begin{tabular}{|c|c|}
\hline GERAÇÃO DOS RESÍDUOS & $\begin{array}{l}\text { Materiais resultantes do processo de assistência à saúde, contendo sangue ou líquidos } \\
\text { corpóreos na forma livre (algodão, gaze, compressas com matéria orgânica, fraldas, sondas } \\
\text { entre outros). Instalações internas da ilpi- fraldas e absorventes higiênicos resultantes das } \\
\text { trocas realizadas nos idosos,máscaras descartáveis, luvas de procedimento, gorros. }\end{array}$ \\
\hline CLASSIFICAÇÃO & $\begin{array}{l}\text { Os resíduos provenientes dos cuidados com residentes suspeitos ou confirmados de } \\
\text { COVID-19 categoria A1 }\end{array}$ \\
\hline SEGREGAÇÃO & $\begin{array}{l}\text { As agulhas e o conjunto seringa-agulha utilizadas na aplicação de vacinas, quando não } \\
\text { desconectadas, devem atender às regras de manejo dos resíduos perfuro cortantes. }\end{array}$ \\
\hline ACONDICIONAMENTO & $\begin{array}{l}\text { No caso das ILPI com tratamento realizado fora da unidade, estes resíduos devem será } \\
\text { condicionados em sacos vermelhos, permanecer armazenados em abrigo para resíduos; }\end{array}$ \\
\hline COLETA E TRANSPORTE INTERNO & $\begin{array}{l}\text { A coleta e o transporte devem atender ao roteiro previamente definido e devem ser feitos } \\
\text { em horários, sempre que factíveis não coincidentes com a distribuição de roupas, alimentos } \\
\text { e medicamentos, períodos de visita ou de maior fluxo de pessoas ou de atividades. A } \\
\text { coleta deve ser feita separadamente, de acordo com o grupo de resíduos e em recipientes } \\
\text { específicos a cada grupo de resíduos. O funcionário devidamente paramentado com EPI }\end{array}$ \\
\hline ARMAZENAMENTO TEMPORÁRIO & $\begin{array}{l}\text { Consiste na guarda temporária dos recipientes contendo os resíduos já acondicionados, em } \\
\text { local próximo aos pontos de geração, visando agilizar a coleta dentro do estabelecimento e } \\
\text { otimizar o deslocamento entre os pontos geradores e o ponto destinado à disponibilização } \\
\text { para coleta externa. } \\
\text { Os sacos contendo tais resíduos devem ser objeto de coleta e transporte especializados } \\
\text { para RSS, e submetidos a processos licenciados de tratamento, antes de sua disposição final }\end{array}$ \\
\hline
\end{tabular}

Ressalta-se ainda que devido ao desconhecimento sobre como e por quanto tempo o Covid-19 pode ser transmitido por contato com os objetos, não é possível sugerir um prazo para quarentena dos materiais recicláveis. Recomenda-se aos s com caso confirmado da Covid-19, não entregar resíduos recicláveis aos catadores, a fim de não expor esses trabalhadores a riscos ${ }^{(5)}$. 


\section{LIMITAÇÕES}

A primeira limitação que o profissional enfermeiro encontrará será a negociação com o gestor financeiro dessas instituições a fazer um investimento cujo retorno será intangível. Segundo, será engajar toda a equipe, principalmente na segregação adequada desses resíduos (segregação adequada diminui a quantidade impedindo a contaminação da massa total dos resíduos gerados). Terceiro elemento a ser considerado é que o idoso também deve fazer parte da construção desse processo visto que podemos esbarrar em questões educacionais e cultuais como o uso de lenços de pano, a falta de entendimento da etiqueta respiratória. Fatores esses que também podem estar presentes na equipe de cuidado.

\section{IMPLICAÇÕES PARA A ENFERMAGEM}

A pandemia por COVID 19 trouxe para os mais diversos cenários de cuidado uma condição em que a falta de um uma terapêutica medicamentosa comprovadamente eficaz, ausência de uma vacina e onde a aplicação de alta tecnologia tem sido indiferente na contenção da curva epidemiológica de mortalidade um aumento da visibilidade da importância do verbo cuidar. Partindo de uma análise ecológica da prática do cuidado pelo enfermeiro na atual conjuntura, é perceptível a capacidade inerente dessa profissão de integrar toda a oferta de cuidado desde a atenção primária á terapia intensiva. Sob o guarda-chuvas de cuidado do enfermeiro está a equipe, o paciente, os familiares e/ou contactantes e o meio ambiente. Ao se falar em gerenciar resíduos gerados em serviços de saúde desde sua origem até seu destino final, falamos de uma cadeia enorme de eventos que precisam ocorrer e que por sua vez dependem de vários sujeitos engajados em uma missão.

\section{CONSIDERAÇÕES FINAIS}

O gerenciamento dos resíduos é de suma importância considerando o grau de transmissibilidade do coronavírus constitui-se em prioridade nas ILPIs para conter a disseminação da COVID-19 no ambiente e comunidade. Implementar um conjunto de procedimentos de gestão com o objetivo de minimizar a produção de resíduos e proporcionar aos resíduos gerados um encaminhamento seguro, de forma eficiente, visando à proteção dos trabalhadores, a preservação da saúde pública, dos recursos naturais e do meio ambiente.

\section{AGRADECIMENTO}

\section{Ao Departamento Científico de Enfermagem Gerontológica da ABEn Nacional.}

\section{REFERENCIAS}

1. Ministério da Saúde (BR), Agência Nacional de Vigilância Sanitária. Resolução RDC/Anvisa n²22/2018. Regulamenta as Boas Práticas de Gerenciamento dos Resíduos de Serviços de Saúde e dá outras providências. Disponível http://portal. anvisa.gov.br/documents/10181/3427425/RDC_222_2018_.pdf/c5d3081d-b331-4626-8448-c9aa426ec410

2. ABNT. NBR 12.810:2016 - Resíduos de serviços de saúde - Gerenciamento extra estabelecimento - Requisitos. Brasil, 2016.

3. Ministério da Saúde (BR), Agência Nacional de Vigilância Sanitária. Orientações para a prevenção e o controle de infecções pelo Novo Coronavírus em Instituições de Longa Permanência para Idosos (ILPI). Brasília (DF): Ministério da Saúde; 2020. Disponível em: https://www20.anvisa.gov.br/segurancadopaciente/index.php/alertas/item/nota-tecnica-n-05-2020gvimsggtes-anvisa-orientacoes-para-a-prevencao-e-o-controle-de-infeccoes-pelo-novo-coronavirus-sars-cov-2-ilpi

4. Agência Nacional de Vigilância Sanitária. Nota técnica n 05/2020- SARS-CoV-2/ANVISA -Orientações para a Prevenção e o Controle de Infecções pelo Novo Coronavírus em instituições de longa permanência para idosos (ILPI). 2020. Disponível: www20.anvisa.gov.brportal.anvisa.gov.br/coronavirus/faq 
5. Agência Nacional de Vigilancia Sanitária. Nota técnica n 04/2020 - sars-cov-2 /ANVISA - Orientações para Serviços de Saúde: medidas de prevenção e controle que devem ser adotadas durante a assistência aos casos suspeitos ou confirmados de infecção pelo novo coronavírus. Disponível em: https://www.anvisa.gov.b/rportal.anvisa.gov.br/ documents/33852/271858/

6. Carta aberta a Comunidade Científica sobre os cuidados da equipe de Enfermagem das Instituições de Longa Permanência para Idosos (ILPIs) para o enfrentamento da disseminação da COVID-19. Disponível em: http://www. abennacional.org.br/.../DCEG-ABEn_Informe_COVID-19...(2020).

7. Resolução Conama n 358, de 29 de abril de 2005 - Dispõe sobre o tratamento e a disposição final dos resíduos dos serviços de saúde. Disponível em: https://www.conama.org.br 